\title{
ARTICLE
}

\section{The intragraft vascularized bone marrow component plays a critical role in tolerance induction after reconstructive transplantation}

\author{
Cheng-Hung Lin (D) ${ }^{1}$, Madonna R. Anggelia ${ }^{1,2}$, Hui-Yun Cheng ${ }^{1}$, Aline Yen Ling Wang ${ }^{1}$, Wen-Yu Chuang ${ }^{3}$, Chih-Hung Lin ${ }^{1,4}$, \\ W. P. Andrew Lee ${ }^{5}$, Fu-Chan Wei ${ }^{1,2}$ and Gerald Brandacher ${ }^{5}$
}

The role of the vascularized bone marrow component as a continuous source of donor-derived hematopoietic stem cells that facilitate tolerance induction of vascularized composite allografts is not completely understood. In this study, vascularized composite tissue allograft transplantation outcomes between recipients receiving either conventional bone marrow transplantation (CBMT) or vascularized bone marrow (VBM) transplantation from Balb/c $(\mathrm{H} 2 \mathrm{~d})$ to $\mathrm{C} 57 \mathrm{BL} / 6(\mathrm{H} 2 \mathrm{~b})$ mice were compared. Either highor low-dose CBMT $\left(1.5 \times 10^{8}\right.$ or $3 \times 10^{7}$ bone marrow cells, respectively) was applied. In addition, recipients were treated with costimulation blockade ( $1 \mathrm{mg}$ anti-CD154 and $0.5 \mathrm{mg}$ CTLA4lg on postoperative days 0 and 2, respectively) and short-term rapamycin ( $3 \mathrm{mg} / \mathrm{kg} /$ day for the first posttransplant week and then every other day for another 3 weeks). Similar to high-dose conventional bone marrow transplantation, 5/6 animals in the vascularized bone marrow group demonstrated long-term allograft survival (>120 days). In contrast, significantly shorter median survival was noted in the low-dose CBMT group ( 64 days). Consistently high chimerism levels were observed in the VBM transplantation group. Notably, low levels of circulating CD4 ${ }^{+}$and $\mathrm{CD}^{+} \mathrm{T}$ cells and a higher ratio of Treg to Teff cells were maintained in VBM transplantation and high-dose CBMT recipients (>30 days) but not in low-dose VBM transplant recipients. Donor-specific hyporesponsiveness was shown in tolerant recipients in vitro. Removal of the vascularized bone marrow component after secondary donor-specific skin transplantation did not affect either primary allograft or secondary skin graft survival.

Keywords: Vascularized composite allotransplantation; Costimulation blockade; Donor-specific tolerance; Vascularized bone marrow transplantation; Chimerism

Cellular \& Molecular Immunology (2021) 18:363-373; https://doi.org/10.1038/s41423-019-0325-y

\section{INTRODUCTION}

Reconstructive transplantation, also referred to as vascularized composite allotransplantation, has emerged as a viable therapeutic option for individuals suffering from devastating tissue loss that is not amenable to conventional reconstructive techniques. ${ }^{1-3}$ Vascularized composite allografts (VCA) may contain any combination of tissues with unique antigenicities, such as skin, muscle, vessels, cartilage, tendon, nerve, bone, and bone marrow (BM). The specific characteristics of the different tissue types pose a challenge for prolonged allograft survival compared to solid organ transplantation. ${ }^{4}$ However, this challenge can generally be met with long-term immunosuppression using high doses of multiple drugs to prevent rejection and graft failure. ${ }^{5}$ Such long-term administration of multiple immunosuppressants often has significant side effects and toxicities, such as infections, metabolic, and even malignant complications. For this reason, the implementation of novel therapies allowing for a reduction in immunosuppressive treatment is vital to tipping the risk-benefit ratio in favor of VCA recipients and expanding the pool of eligible patients. ${ }^{6}$ Particularly appealing for overcoming this dilemma are various cell-based approaches to induce mixed chimerism and transplant tolerance. ${ }^{7-10}$ This is conventionally accomplished with transplantation of donor-derived BM cells to the recipient to induce chimerism. ${ }^{1-13}$ Conditioning therapies with less toxicity can now be used with adjunctive allogeneic BM transplantation. ${ }^{14}$ VCAs are uniquely aligned with many current cell-based tolerance approaches because they contain a vascularized bone marrow (VBM) niche. ${ }^{8}$ These compartments constitute a continuous source of hematopoietic progenitor cells of donor origin that may aid in the development of mixed chimerism or host a number of regulatory mechanisms that contribute to immune regulation and transplant tolerance.

\footnotetext{
${ }^{1}$ Center for Vascularized Composite Allotransplantation, Department of Plastic and Reconstructive Surgery, Chang Gung Memorial Hospital, Chang Gung Medical College and Chang Gung University, Taoyuan, Taiwan, China; ${ }^{2}$ Graduate Institute of Biomedical Sciences, College of Medicine, Chang Gung University, Taoyuan, Taiwan, China; ${ }^{3}$ Department of Pathology, Chang Gung Memorial Hospital, Chang Gung Medical College and Chang Gung University, Taoyuan, Taiwan, China; ${ }^{4}$ Department of Plastic and Reconstructive Surgery, Chiayi Chang Gung Memorial Hospital, Chiayi County, Taiwan, China and ${ }^{5}$ Department of Plastic and Reconstructive Surgery, Vascularized Composite Allotransplantation (VCA) Laboratory, Johns Hopkins University School of Medicine, Baltimore, MD, United States

Correspondence: Fu-Chan Wei (fuchanwei@gmail.com) or Gerald Brandacher (brandacher@jhmi.edu)

These authors contributed equally: Cheng-Hung Lin, Madonna R. Anggelia
}

Received: 20 March 2019 Accepted: 20 October 2019

Published online: 21 November 2019 
Recent progress in vascularized composite allotransplantation science further promotes the concept that transplantation of an intragraft VBM component could be an enhancement and has superior effects than conventional bone marrow transplantation (CBMT). ${ }^{15,16}$ Specifically, VBM may provide both structural and immunologic advantages. In VBM, the natural stromal microenvironment of BM cells is preserved. ${ }^{17-19}$ The stromal microenvironment or niche provides trophic support for cell proliferation and may play an important regulatory role in lymphocyte function and transplant immunology. ${ }^{20-22}$ Compared to intravenous donor BM cell infusion, VBM has been shown to facilitate donor cell expansion in the BM cavities of lethally irradiated rats. ${ }^{18}$ At present, either replicating or manipulating stromal cells ex vivo is not clinically feasible. ${ }^{23-25}$

Thus the purpose of this study was to compare the effect of VBM and CBMT on allograft survival and tolerance induction in an established murine VCA model under a combined costimulation blockade (CoB) and short-term rapamycin (RPM) immunosuppression regimen.

\section{RESULTS}

Combined $\mathrm{CoB}$ and short-term RPM treatment resulted in longterm allograft survival in VBM and high CBMT but not in low CBMT recipients

In this study, we compared the efficacy of CBMT and VBM transplantation in prolonging allograft survival. We were able to obtain $\sim 3 \times 10^{7}$ BM cells from 1 femoral bone. Thus this quantity of isolated BM cells in addition to allogeneic myocutaneous (alloMC) flap was applied to the low CBMT group. On the other hand, the high CBMT group received $1.5 \times 10^{8} \mathrm{BM}$ cells, which is equal to a fivefold higher number of BM cells than that in the low CBMT group. As a positive control group, all syngeneic recipients (4/4) accepted their grafts indefinitely without any signs of rejection. As a negative control group, recipients without CBMT or the vascularized bone component experienced early graft rejection with a median survival time (MST) of 59 days. Graft rejection was shown as skin erythema/necrosis and complete hair loss. Low-dose CBMT only slightly prolonged graft survival to an MST of 64 days. In contrast, recipients in both the high CBMT (5/6) and VBM transplantation (5/6) groups exhibited long-term allograft survival, which was clinically evident as normal hair growth and healthy transplanted skin through the entire observation period until postoperative day (POD) 120 (Fig. 1C, d).

VBM transplantation and high CBMT induce multilineage chimerism

At POD 30, recipients in the high CBMT as well as the VBM transplantation groups demonstrated comparable levels of mixed chimerism of $4.2 \%$ (range $4.1-4.8 \%$ ) and $3.8 \%$ (range $2.2-6.5 \%$ ) circulating donor leukocytes, respectively. In contrast, the group with low CBMT did not show evidence of chimerism [0.07\% (range $0.05-0.10 \%)$ ], and recipients in this group only showed low levels of donor cells [1.7\% (range 0.9-2.3\%)] (Fig. 2a). Figure 2b illustrates the trends in lymphoid and myeloid chimerism of the recipients with accepted VCA at the designated time points (PODs 30, 60, 90, and 120). Furthermore, we found that chimerism levels drastically declined before VCA rejection in the low CBMT group. In contrast, the high CBMT and VBM transplantation groups did not show such a trend. Of note, the majority of the donor-derived lymphocytes consisted of B cells (CD19+) in all the groups (Fig. 2c).

Chimerism generated by donor BM was detected in multiple lymphoid organs

To explore the underlying mechanisms of establishment and maintenance of immune tolerance to VCA in this model, various tissues were analyzed for chimerism. Both immunohistochemistry $(\mathrm{IHC})$ and flow cytometry supported the presence of donor cells in the thymus, lymph nodes (LNs), and spleen of recipients in all the groups (Fig. 3a). The percentages of donor cells in lymphoid tissues and the graft bone compartment in recipient mice from the low CBMT group at the time of rejection were as follows: thymus: $0.02 \%$ (range $0.01-0.05 \%$ ); LN: $0.4 \%$ (range $0.2-0.5 \%$ ); spleen: $0.98 \%$ (range $0.20-1.01 \%$ ); bone: $0.48 \%$ (range $0.18-0.83 \%)$. These levels were significantly lower than those in mice of the VBM transplantation group [thymus: $0.32 \%$ (range $0.11-0.87 \%$ ); LN: $3.2 \%$ (range $1.5-4.5 \%$ ); spleen: $3.7 \%$ (range 2.7-6.9\%); bone: $2.2 \%$ (range 1.2-3.9\%)] at POD 120. However, chimerism levels in recipient mice of the high CBMT group [thymus: $0.34 \%$ (range $0.24-0.59 \%$ ); LN: $2.1 \%$ (range $1.8-2.8 \%$ ); spleen: $2.5 \%$ (range 2.4-2.7\%); bone: $2.1 \%$ (range 1.7-4.3\%)] were comparable to levels in the VBM transplantation group (Fig. $3 \mathrm{a}, \mathrm{b}$ ). In addition, the levels of $\mathrm{V} \beta 5.1 / 2^{+}$and $\mathrm{V} \beta 11^{+} \mathrm{CD} 4^{+}$ $T$ cells in the thymus, LNs, and spleen in the VBM transplantation group were similar to those in the high CBMT group but significantly lower than those in the low CBMT group (Fig. 3c).

Groups other than the low CBMT group showed maintained CD4 and CD8 suppression

Peripheral $\mathrm{CD}^{+}, \mathrm{CD}^{+}{ }^{+}$, and $\mathrm{CD} 4^{+} \mathrm{CD} 25^{+} \mathrm{Foxp}^{+} \mathrm{T}$ cell populations were measured in recipients using flow cytometry. The recipients receiving both CBMT and VBM transplantation demonstrated reduced populations of $\mathrm{CD}^{+}$and $\mathrm{CD}^{+}$cells at POD 30 [7\% (range 6.9-7.4\%) and 8\% (range $7.4-9.5 \%$ ); $8.4 \%$ (range 7.1-14.1\%) and $8.7 \%$ (range 6-12.1\%); 4.9\% (range 4.3-7.5\%) and 6.7\% (range 5.7-9.5\%)] in comparison to naive animals $[24.3 \%$ (range $21.1-25.6 \%$ ) and $19.9 \%$ (range 15.4-22\%)]. The group with no CBMT showed reduced populations of $\mathrm{CD}^{+}\left[8.9 \%\right.$ (range $8.1-13.1 \%$ )] but not $\mathrm{CD}^{+}{ }^{+}[21.7 \%$ (range 8.4-31.8\%)] in comparison with naive controls (Fig. 4a). However, at POD 60, the low CBMT recipients showed rebound proliferation of $\mathrm{CD}^{+}$and $\mathrm{CD}^{+}$cells $[20 \%$ (range $7.1-29.3 \%$ ) and $13.6 \%$ (range $11.3-29.3 \%$ ), respectively], whereas $\mathrm{CD}^{+}$and $\mathrm{CD}^{+}$stayed suppressed in recipients of the VBM transplantation group [7.1\% (range 5.7-9.4\%) and $8.6 \%$ (range 5.3-9.5\%)] $(p<0.05)$ (Fig. 4b). CD4 ${ }^{+} \mathrm{CD} 25^{+}$Foxp $^{+}$T cells at POD 30 were found to be elevated in all the groups, although only the increase in the VBM transplantation group showed statistical significance when compared to the level at POD $0[8.1 \%$ (range $6.6-9.1 \%$ ) vs $4.7 \%$ (range $4.4-5.0 \%$ )]. Notably, the ratio of $\mathrm{CD}^{+} \mathrm{CD}_{25}{ }^{+} \mathrm{Foxp}^{+}$regulatory $\mathrm{T}$ cells (Tregs) to the $\mathrm{CD}^{+}$ and $\mathrm{CD}^{+} \mathrm{T}$ cell populations in the VBM transplantation group remained elevated, although the percentage of $\mathrm{CD}^{+}{ }^{+} \mathrm{CD} 25^{+}$Foxp $^{+}$Tregs in whole lymphocytes decreased to that of naive mice. After POD 60, the ratio of $\mathrm{CD} 4{ }^{+} \mathrm{CD} 25^{+} \mathrm{Foxp} 3^{+}$ Tregs to effector T cells was still significantly higher compared to that of naive cells (Fig. 4c). Using IHC, graft-residing Foxp3 ${ }^{+}$ cells were detected in the high CBMT group and the VBM transplantation group (Fig. 4d). In addition, the levels of $\mathrm{V} \beta 5.1 / 2^{+}$and $\mathrm{V} \beta 11^{+} \mathrm{CD} 4^{+} \mathrm{T}$ cells from the VBM transplantation group and the group receiving high CBMT were comparable. In contrast, the low CBMT group had significantly higher levels of $\mathrm{V} \beta 5.1 / 2^{+}$and $\mathrm{V} \beta 11^{+} \mathrm{CD} 4^{+} \mathrm{T}$ cells (Fig. 4e).

Donor-specific hyporesponsiveness of $\mathrm{CD}^{+}$and $\mathrm{CD} 8^{+}$cells was evident in the VBM transplantation and high-dose CBMT groups The proliferative potential of recipient cells in the VBM transplantation group against donor or third-party antigens was examined by the mixed lymphocyte reaction (MLR) in vitro. Cells from naive animals served as controls. CD4 ${ }^{+}$and $\mathrm{CD}^{+}$cells from the spleen and LNs of tolerant VCA recipients showed donor-specific 


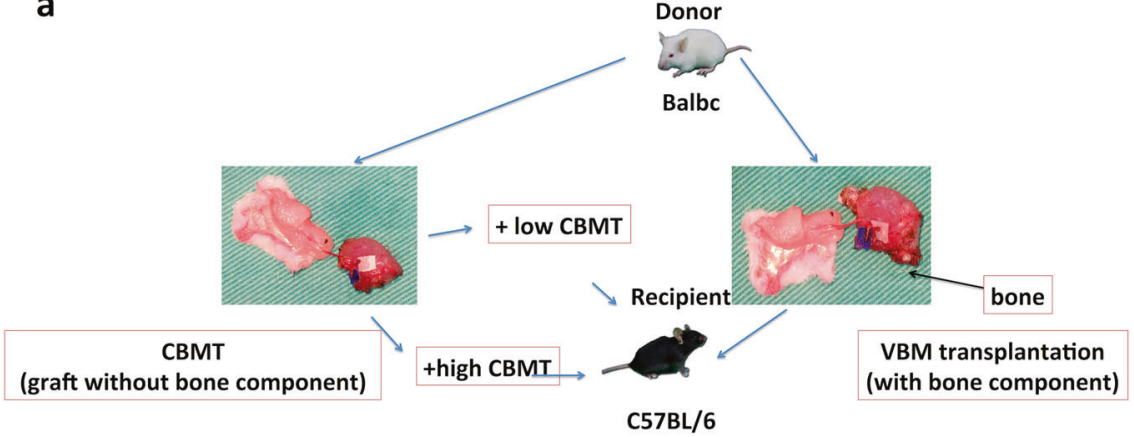

b

Anti-CD154, $1 \mathrm{mg}$ i.p.

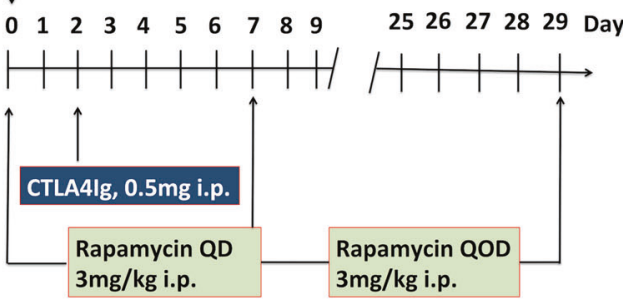

C
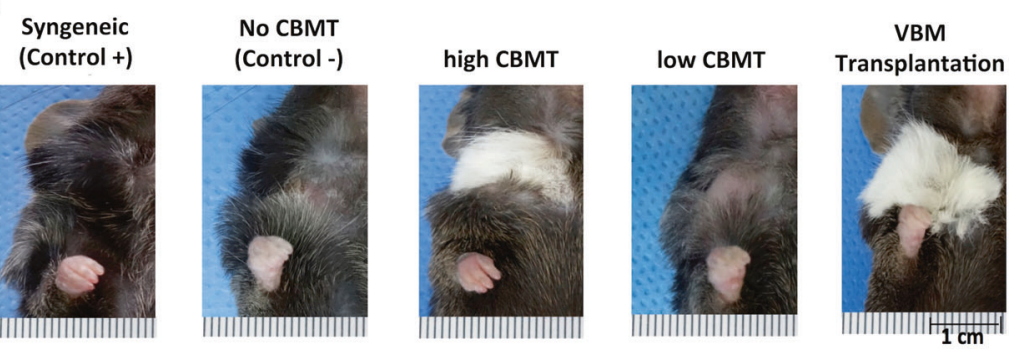

d

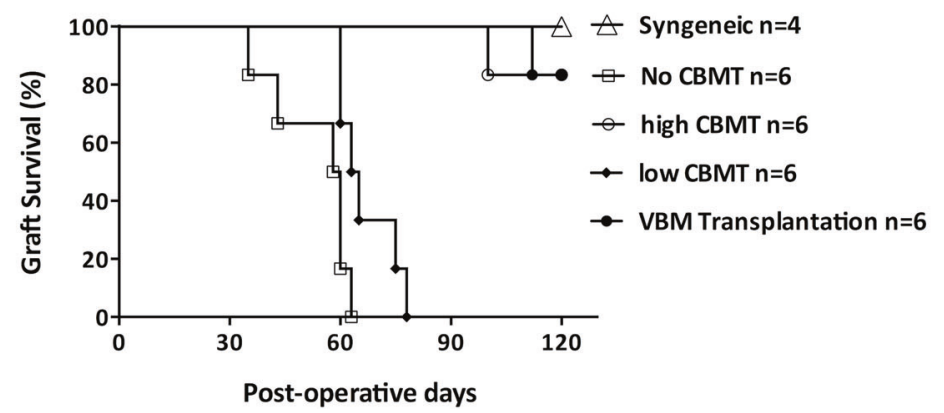

Fig. 1 VBM transplantation with COB and RPM resulted in prolonged VCA survival. a Experimental design. b Immunosuppression protocol. c Graft tolerance in the high CBMT and VBM transplantation groups is represented clinically by normal hair growth. In contrast, graft rejection in the no CBMT and low CBMT groups showed erythema and hair loss of the transplanted flap. d Kaplan-Meier survival analysis of flaps in the syngeneic group, $n=4$; alloMC group, $n=6$; high CBMT group, $n=6$; low CBMT group, $n=6$; and VBM transplantation group, $n=6$. The no CBMT group vs VBM transplantation group and low CBMT group vs VBM transplantation group were significantly different $(p<0.05)$.

hyporesponsiveness in comparison to the response to a thirdparty antigen $\left[\mathrm{CD}^{+}: 4.7 \%\right.$ (range $2.3-5.4 \%$ ) vs $14.3 \%$ (range 9.8-23.7); $\mathrm{CD}^{+}: 4.6 \%$ (range $4.4-6.4 \%$ ) vs $34 \%$ (range $27.4-40.4 \%)](p<0.05$, Fig. 5). In contrast, cells from the recipients that rejected their VCA (low CBMT group) had comparable proliferation responses to donor and third-party antigens [CD4 ${ }^{+}$: $12.5 \%$ (range $1.8-16.3 \%$ ) vs $17 \%(12.9-21.6 \%)$; CD8 ${ }^{+}: 25.2 \%$ (range $17.6-30.9 \%$ ) vs $24.4 \%$ (range $21.9-28.3 \%)]$.
Donor-specific tolerance was maintained after removal of the osteomyocutaneous (OMC) flap

In a previous publication by our group, the VBM transplantation model showed donor-specific tolerance in vivo after secondary skin allograft challenge. ${ }^{26}$ In this study, donor-derived skin graft transplantation was performed on the same day (day 0) or 30 and 90 days after VBM transplantation. The VCA transplanted on day 0 was then removed at 1 month after skin graft transplantation 

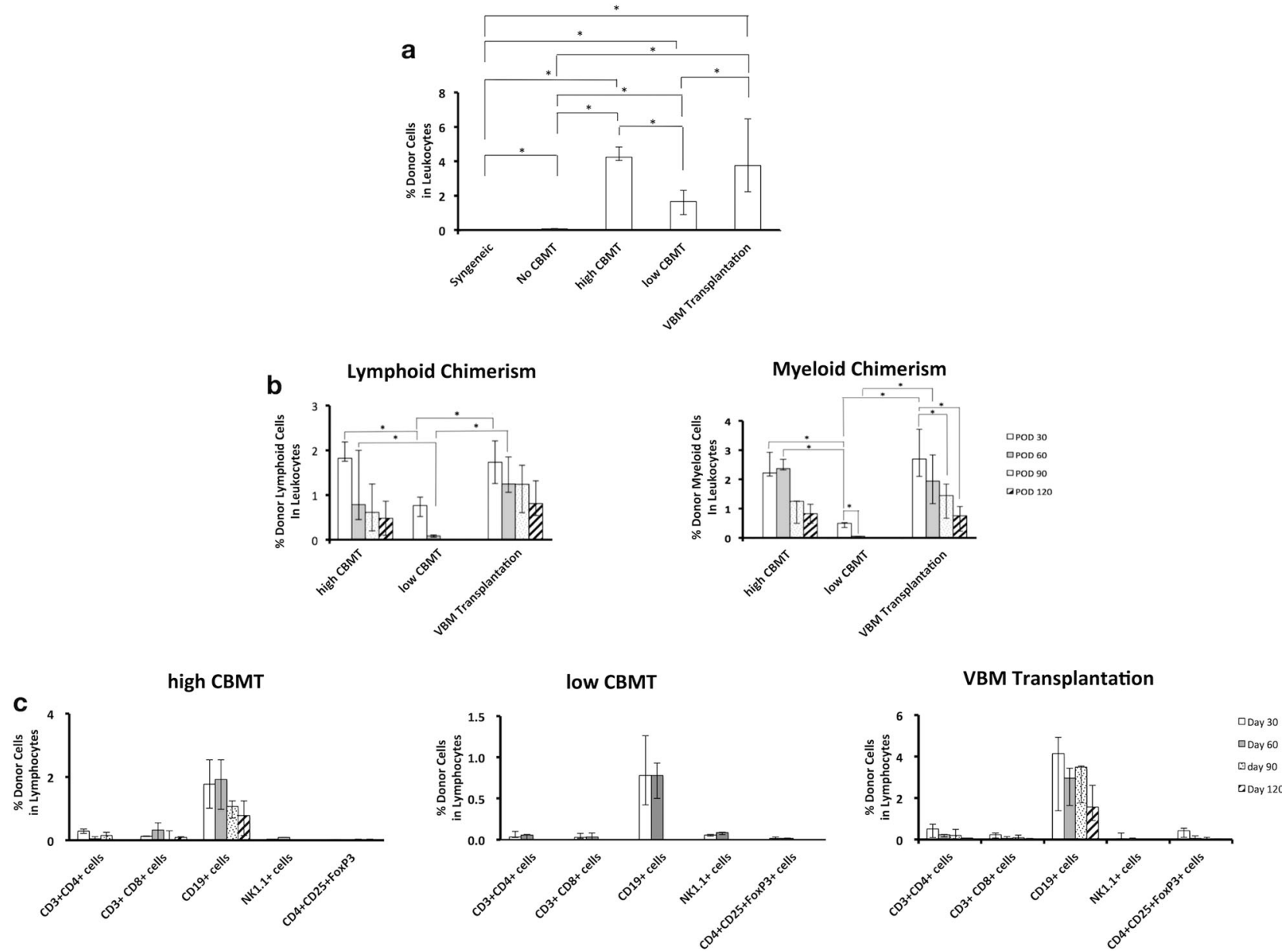

Fig. 2 Peripheral chimerism. a Leukocyte chimerism in the peripheral blood of recipients among different groups at POD 30 . $\mathbf{b}$ Grouped data of multilineage chimerism and c subpopulation of lymphoid cells in peripheral blood of the high CBMT, low CBMT, and VBM transplantation recipients with long-term VCA survival of 120 days following transplantation. Data are expressed as the median and range in the syngeneic group, $n=4$; no CBMT group, $n=6$; high CBMT group, $n=6$; low CBMT group, $n=6$; and VBM transplantation group, $n=6$. The asterisk denotes statistical significance $(p<0.05)$.

(Fig. 6a). We found that survival of the skin allograft ( $>60$ days) was not affected by removal of the OMC flap (Fig. 6b, c). The levels of chimerism preremoval of the OMC flap at PODs 30,60, and 120 were $4.3 \%$ (range $2.2-5.9 \%$ ), $1.7 \%$ (range $1.1-2.1 \%$ ), and $1.7 \%$ (range $0.86-2.2 \%$ ), respectively (Fig. $7 \mathrm{a}, \mathrm{b}$ ). The levels of chimerism after removal of the OMC flap at PODs 30,60, and 120 were $0.03 \%$ (range $0.01-0.05 \%$ ), $0.04 \%$ (range $0.03-0.07 \%$ ), and $0.03 \%$ (range $0.01-0.05 \%$ ), respectively (Fig. $7 \mathrm{~b}$ ). The loss of chimerism post removal of the OMC flap was confirmed. However, the peripheral lymphocyte panel did not change significantly following OMC flap removal in the VBM transplant recipient group ( $p>0.05$, Fig. 7c). These data suggest that donor-specific tolerance was preserved in the VBM transplantation recipient group even after OMC explantation and loss of chimerism.

\section{DISCUSSION}

In this study, we directly compared the efficacy of CBMT vs VBM transplantation to establish mixed chimerism and to induce immune tolerance in a vascularized composite allotransplantation model. Although previous studies showed that irradiation was required to prevent rejection following low-dose $\mathrm{CBMT}^{27,28}$ we demonstrated that myeloablative preconditioning (such as irradiation) was not a prerequisite for establishing chimerism and prolonging allograft survival in VBM transplantation. Thus CBMT was performed without irradiation in this study for comparison purposes. ${ }^{26,29}$ We found that infusion of $3 \times 10^{7}$ bone cells from one femur bone only mildly prolonged VCA survival (MST 64 days) under a nonlymphodepletive immunosuppression protocol, suggesting the superior efficacy of VBM transplantation to CBMT. However, we were able to demonstrate that CBMT can induce long-term allograft survival as reliably as VBMT when the infused cell number was increased to fivefold of the average cell numbers that could be obtained from a single femur bone in this model. Notably, VCA survival was not altered when the VBM component was removed at 1 month after secondary donorspecific skin transplantation, suggesting that the short-term presence of VBM and transient chimerism may be sufficient to induce tolerance in this setting.

VCA differs from solid organ allotransplantation because it contains multiple tissue types, often including a highly antigenic skin component, ${ }^{30}$ and thus presents both immunological challenges and unique opportunities for immune regulation. Previous data have shown that the combination of $\mathrm{CoB}, \mathrm{BM}$ transplantation, and short-term immunosuppression prolong the survival of skin and intestinal allografts. ${ }^{31}$ In addition, in various VBM transplantation models, ${ }^{26,32-36}$ several protocols have been reported for inducing tolerance. BM in its native environment (1) provides a continuous supply of donor-derived hematopoietic progenitor cells and (2) leads to better and faster reconstitution in recipients compared to an equal dose of isolated marrow cells. ${ }^{18}$ In particular, stromal cells within the transplanted vascularized 
a
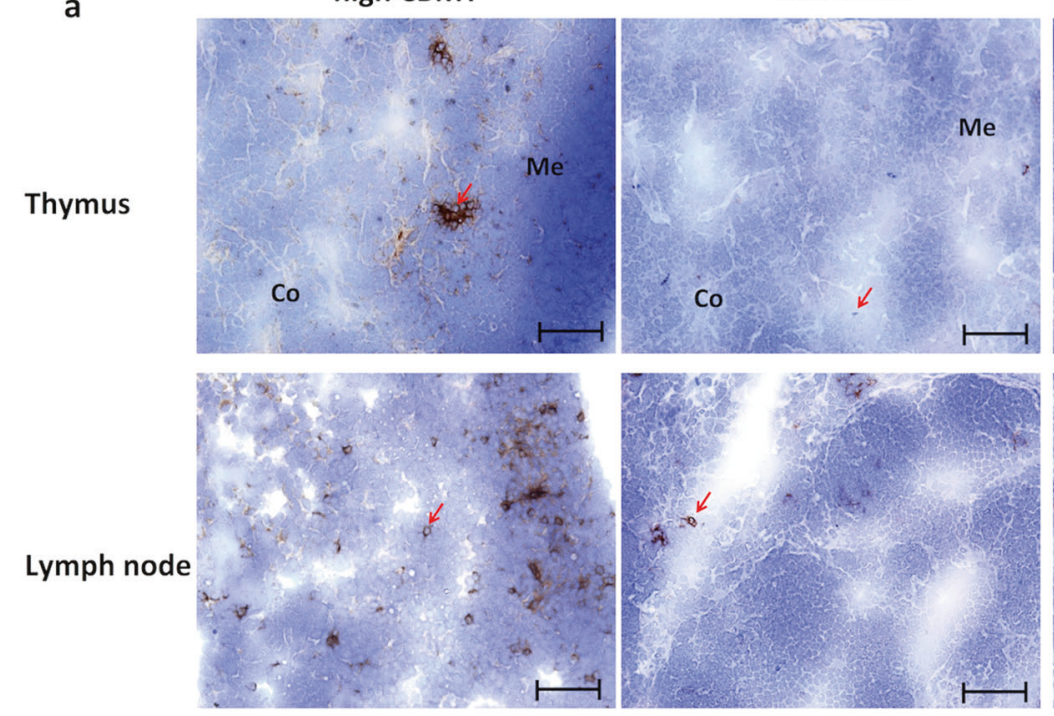

VBM Transplantation
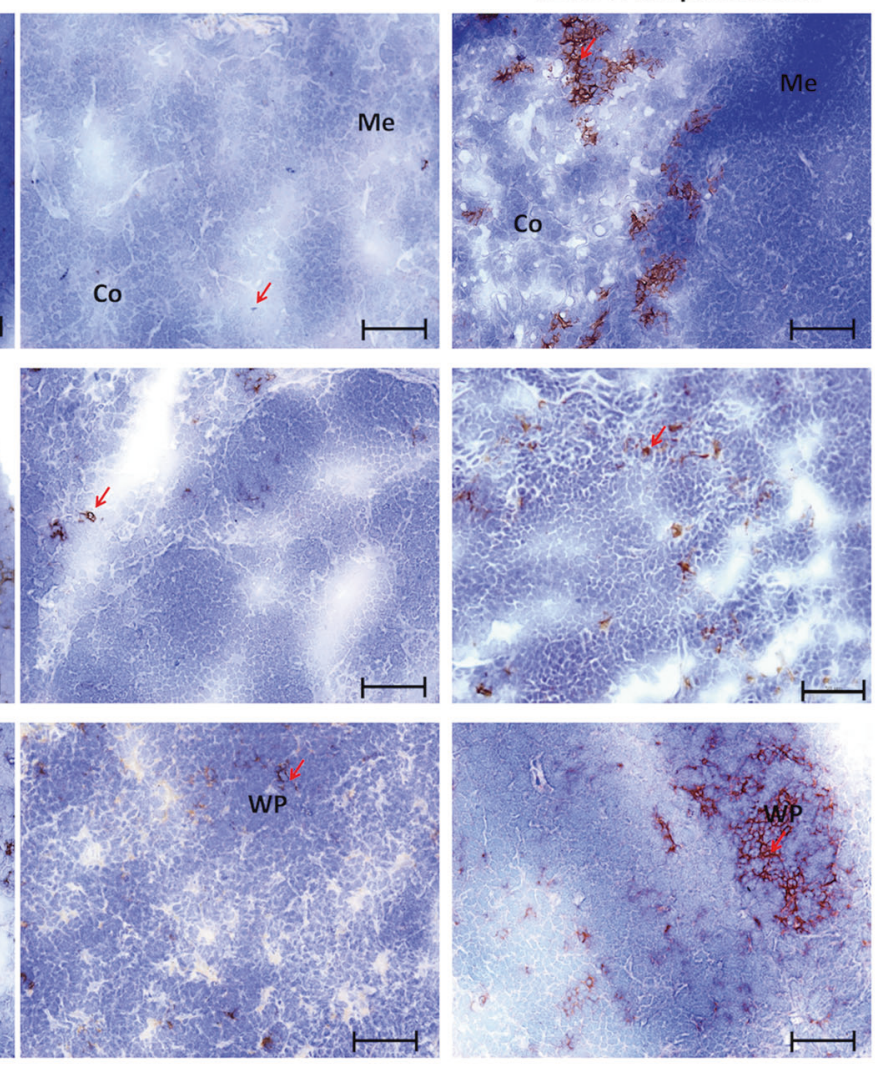

b

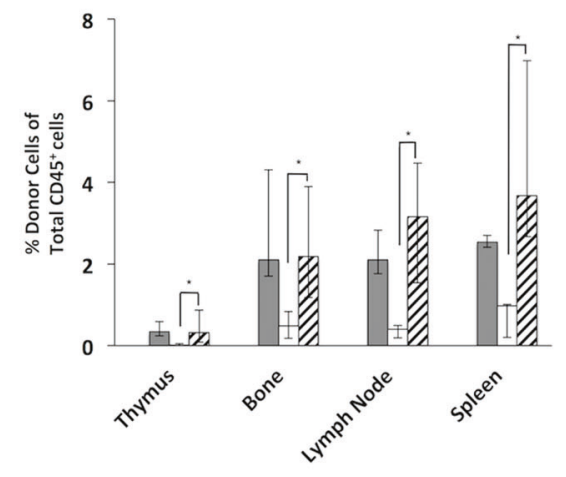

$\square$ high СВMт , n=6

$\square$ low СBMT, $n=6$

G VBM Transplantation, $n=6$

c
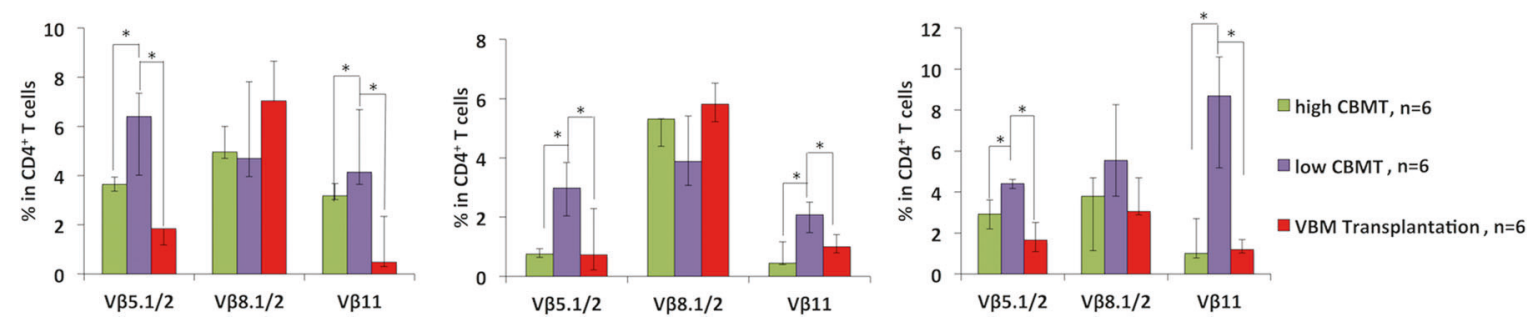

Fig. 3 Chimerism was detected in the thymus, bone marrow, lymph nodes, and spleen of VBM transplantation recipients. a Immunohistochemical staining was performed of MHC class II donor cells (IAd) in the thymus, lymph nodes, and spleen of VCA recipients collected at POD 120 or at the time of rejection. Red arrows indicate donor-derived cells. The results are representative of three mice per group. Co cortex, Me medulla, WP white pulp. Scale bar: $50 \mu \mathrm{m}$; magnification: $\times 400$. Positive cells are indicated by red arrows. b Flow cytometric analysis of donor cells $(\mathrm{H} 2 \mathrm{~d})$ residing in the thymus, bone, lymph nodes, and spleen of VCA recipients. c Expression of TCR V $\beta$ on $\mathrm{CD}^{+} \mathrm{T}$ cells in the spleen, lymph nodes, and thymus. Data are expressed as the median and range in the high CBMT group, $n=4$; low CBMT group, $n=6$; and VBM transplantation group, $n=6$. The asterisk denotes statistical significance $(p<0.05)$. 
C.-H. Lin et al.
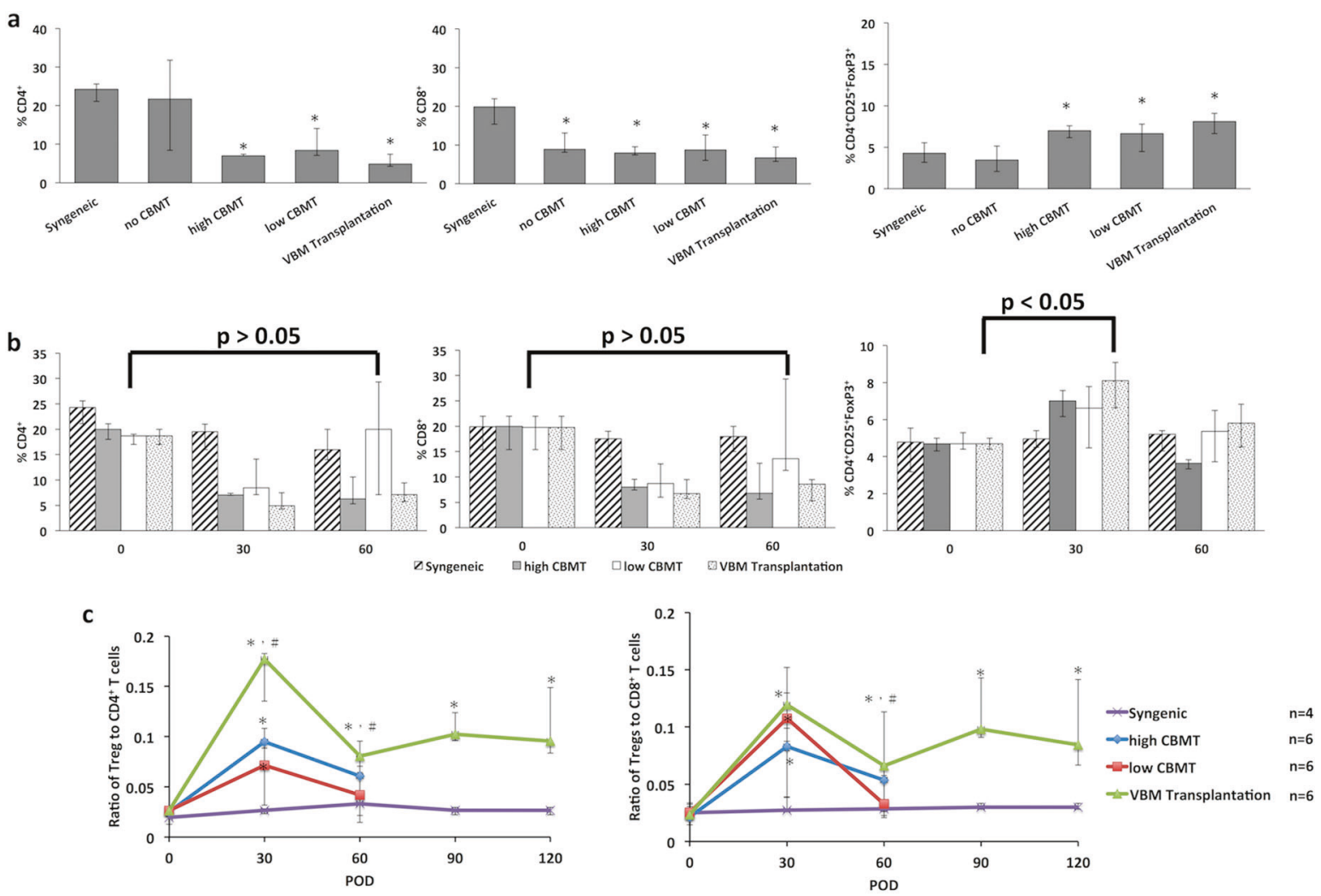

d
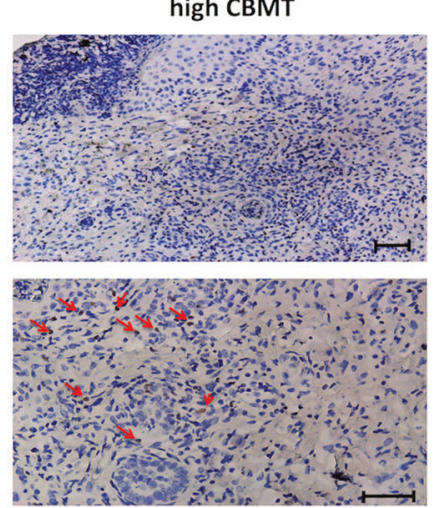

low CBMT
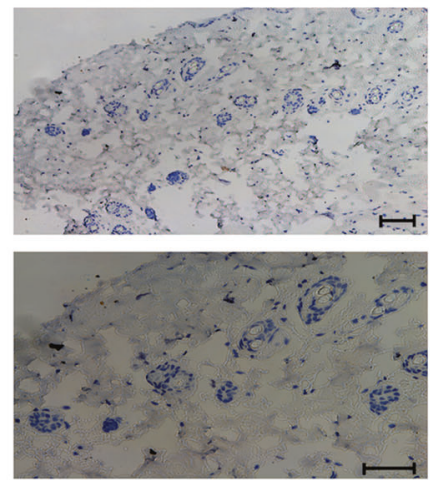

VBM Transplantation
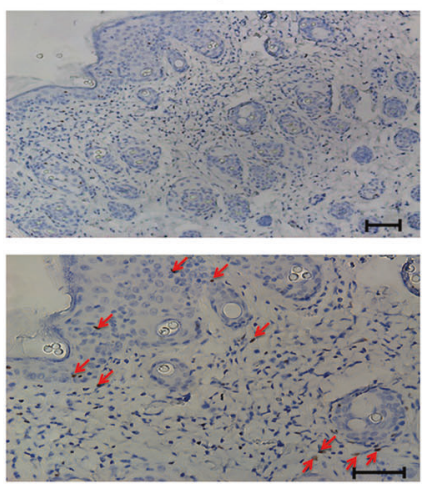

e

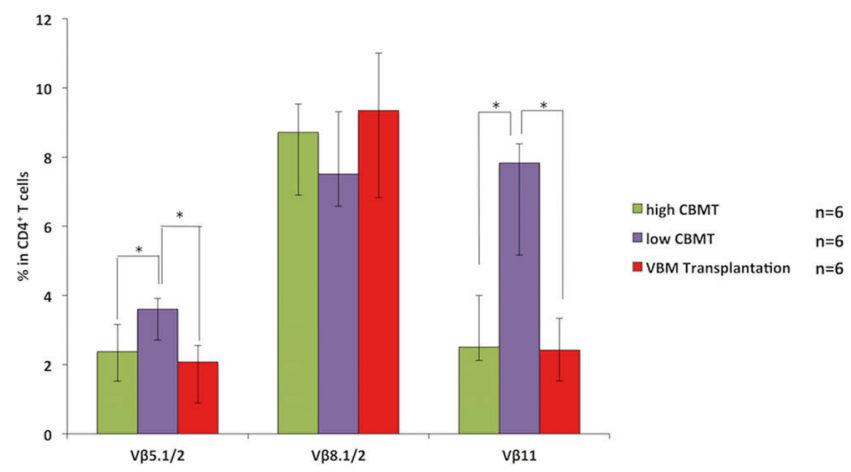

Fig. 4 Changes in specific peripheral cell populations were maintained in VBM transplantation recipients. a Trends in the level of changes in $\mathrm{CD}^{+}, \mathrm{CD}^{+}$, and Tregs $\left(\mathrm{CD} 4^{+} \mathrm{CD} 25^{+} \mathrm{Foxp}^{+}\right)$were similar in the high CBMT $(n=6)$, low CBMT $(n=6)$, and VBM transplantation $(n=6)$ groups at POD 30. b Comparison of CD4 ${ }^{+}, \mathrm{CD}^{+}$, and Treg $\left(\mathrm{CD} 4^{+} \mathrm{CD} 25^{+}\right.$Foxp $\left.3^{+}\right)$cells after low CBMT and VBM transplantation at POD 30 and 60. c Ratio of Tregs to $\mathrm{CD}^{+}$and $\mathrm{CD} 8^{+} \mathrm{T}$ cells. $\mathbf{d}$ Foxp3 $3^{+}$cell detection in the skin of the OMC flap. e Expression of TCR V $\beta$ on CD4 ${ }^{+} \mathrm{T}$ cells in the peripheral blood at POD 30 . In $\mathbf{a}, \mathbf{b}$, the asterisk denotes statistical significance $(p<0.05)$. In $\mathbf{c}$, the asterisk and hash (\#) denote statistical significance compared to the syngeneic and low CBMT groups, respectively $(p<0.05)$. In $\mathbf{d}$, the red arrows indicate Foxp $3^{+}$cells (brown color in the cell nucleus). The IHC results are representative of three mice per group. Scale bar: $50 \mu$ m; magnification: $\times 200$ (above) and 400 (below). In $\mathbf{e}$, the asterisks denote statistical significance compared to the low CBMT group $(p<0.05)$. 

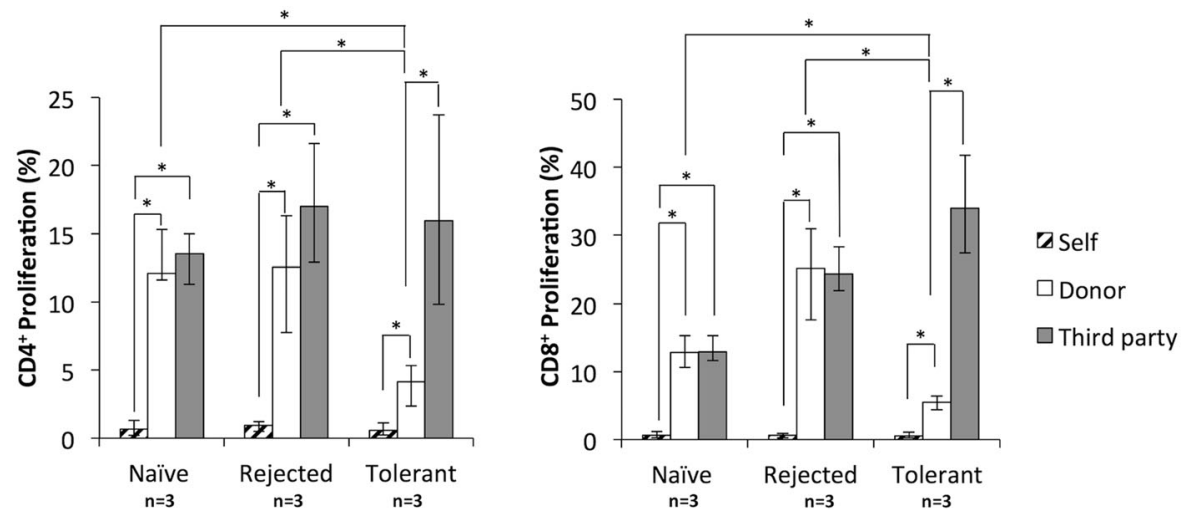

Fig. $5 \mathrm{CD}^{+}$and $\mathrm{CD}^{+}$cells from recipients with long-term surviving grafts demonstrated donor-specific hyporesponsiveness in vitro in an MLR assay. The naive group was an animal without transplantation, and rejected and tolerant animals were derived from the VBM transplantation group. Data are expressed as the median and range from three independent experiments. The asterisk denotes statistical significance $(p<0.05)$.

bone component may support progenitor cell growth and differentiation. ${ }^{37,38}$ Such an advantage of VBM transplantation with regard to chimerism induction and maintenance is supported by our data showing significantly higher peripheral donor cell concentrations in VBM recipients than those with a comparable dose of CBMT and MC allograft recipients. Moreover, the majority of donor-derived cells in recipient peripheral blood were CD19 ${ }^{+}$. This is consistent with our unpublished data showing that the majority of cells residing in the femoral bone are $\mathrm{CD} 19^{+}$ cells (data not shown). Forty percent $\mathrm{CD} 19^{+} \mathrm{CD} 20^{+}$cells were detected in mouse $\mathrm{BM}^{39}$ Plasmablasts that express $\mathrm{CD} 19^{+} \mathrm{CD}_{20} \mathrm{CD}^{-} 8^{+} \mathrm{CD} 138^{+}$accumulate in niches such as BM. ${ }^{40}$

Preservation of the donor BM microenvironment maintains the proliferative capacity of marrow and a continuum of donor cells for dispatch to different recipient compartments. ${ }^{41-44}$ We were able to identify donor cells in the LNs, spleen, and thymus of tolerant recipients. Among the lymphoid organs, the thymus is most important for T cell differentiation. ${ }^{45}$ We hypothesize that prolongation of allograft survival involves both depletion of alloreactive $T$ cells and education of naive immune cells within the thymus, with functional regulation that diminishes rejection. It has been previously reported that a reduction in $\mathrm{V} \beta 5.1 / 2^{+} \mathrm{CD} 4^{+} \mathrm{T}$ cells and $\mathrm{V} \beta 11^{+} \mathrm{CD} 4^{+} \mathrm{T}$ cells could be used as a predictive marker for tolerance. ${ }^{46}$ In this study, we also found that V $\beta 5.1 / 2^{+} \mathrm{CD}^{+} \mathrm{T}$ cells and $\mathrm{V} \beta 11^{+} \mathrm{CD}^{+} \mathrm{T}$ cells in VBM transplantation recipients were significantly decreased in the thymus, spleen, LNs, and peripheral blood. In our previous publication, the percentages of $\mathrm{V} \beta 5.1 / 2^{+}$ $\mathrm{CD}^{+}{ }^{+} \mathrm{T}$ cells in the peripheral blood and within the thymus were reduced in tolerant mice compared to percentages in naive $\mathrm{B} 6$ mice and recipients that rejected their allograft. ${ }^{26}$ This is further supported by previous reports showing that, in a nonhuman primate VCA model, VBM was able to reduce immunosuppressive requirements and improve outcomes, ${ }^{47}$ whereas infused BM cells failed to protect the VCA. ${ }^{48}$

RPM possesses potent immunosuppressive and antiinflammatory properties. ${ }^{49}$ It has been shown to selectively preserve murine and human $\mathrm{CD} 4^{+} \mathrm{CD} 25^{+} \mathrm{Foxp}^{+}$Tregs, thereby inhibiting effector T cell expansion. ${ }^{50,51}$ In this study, RPM and CoB synergized to suppress alloantigen-triggered $\mathrm{CD} 4^{+}$and $\mathrm{CD} 8^{+}$cell proliferation and support $\mathrm{CD} 4^{+} \mathrm{CD} 25^{+}$Foxp $3^{+}$Tregs soon after VBM and low CBMT. It is notable that the effect was lost in low CBMT recipients that showed $\mathrm{CD}^{+}$and $\mathrm{CD}^{+}$cell proliferation, $\mathrm{CD}^{+} \mathrm{CD}^{2} 5^{+}$Foxp $^{+}$Treg suppression, and graft rejection at POD 60. However, long-term suppression of $\mathrm{CD}^{+}$and $\mathrm{CD}^{+}$cells was evident in VBM recipients. In addition, the ratio of $\mathrm{CD}^{+}{ }^{+} \mathrm{CD} 25^{+}$Foxp3 $^{+}$Tregs to the $\mathrm{CD}^{+}$and $\mathrm{CD}^{+} \mathrm{T}$ cell populations remained elevated, although the percentage of $\mathrm{CD}^{+} \mathrm{CD} 25^{+}$Foxp3 $^{+}$Tregs in whole lymphocytes decreased to that of naive mice. The latter indicates that Tregs from tolerant animals may have more suppressive capability of donor alloantigen compared with those from rejecting animals. This corroborates evidence from a recent study in which Tregs from both tolerant and rejecting animals suppressed lymphocyte proliferation, but Tregs from the spleens of acceptors more potently suppressed lymphocyte proliferation than Tregs from rejectors in the presence of donor stimulator cells (unpublished work).

However, the major difference between VBM and low CBMT in our model, which both contain a similar number of BM cells, is that of a preserved BM compartment/niche in the VBM transplantation setting. Hence, we investigated whether this component needs to be preserved over the lifespan of the transplant to maintain tolerance. We found that donor-specific tolerance, as evidenced by skin allograft survival, persisted even after removal of the VBM component. This suggests that the donor $\mathrm{BM}$ compartment is only a temporary requirement for tolerance induction in VCA; once chimerism is established in the recipient, the vascularized bone component seems to not be a critical requirement to maintain the tolerant state. This is further supported by insignificant changes in the levels of circulating lymphocytes in the peripheral blood following removal of the VBM component. Moreover, the results showed that, although the VBM component was removed in the early stage after transplantation (POD 30), this was sufficient to educate the recipient immune system, as evidenced by the acceptance of the secondary skin allograft.

In summary, unlike low-dose CBMT, VBM transplantation effectively induces long-term donor-specific tolerance in mice receiving a vascularized composite allograft (VAS) combined with an anti-CD154/CD28-based CoB therapy and a short-term RPM regimen. Further investigation of the mechanisms underlying this beneficial and protolerogenic effect of an intact VBM compartment and niche in VCA is warranted.

\section{MATERIALS AND METHODS}

Mice

Eight-to-12-week-old male $\mathrm{C} 57 \mathrm{BL} / 6\left(\mathrm{H}_{2}{ }^{\mathrm{b}}\right), \mathrm{Balb} / \mathrm{c}\left(\mathrm{H}_{2}{ }^{\mathrm{d}}\right)$, and $\mathrm{C} 3 \mathrm{H}$ $\left(\mathrm{H} 2^{\mathrm{k}}\right)$ mice were purchased from the National Laboratory Animal Center in Taiwan, China. Animals were housed in pyrogen-free conditions under controlled temperature and lighting cycles with water and commercial mouse chow available ad libitum at the Chang Gung Memorial Hospital Animal Center. All experiments 
a
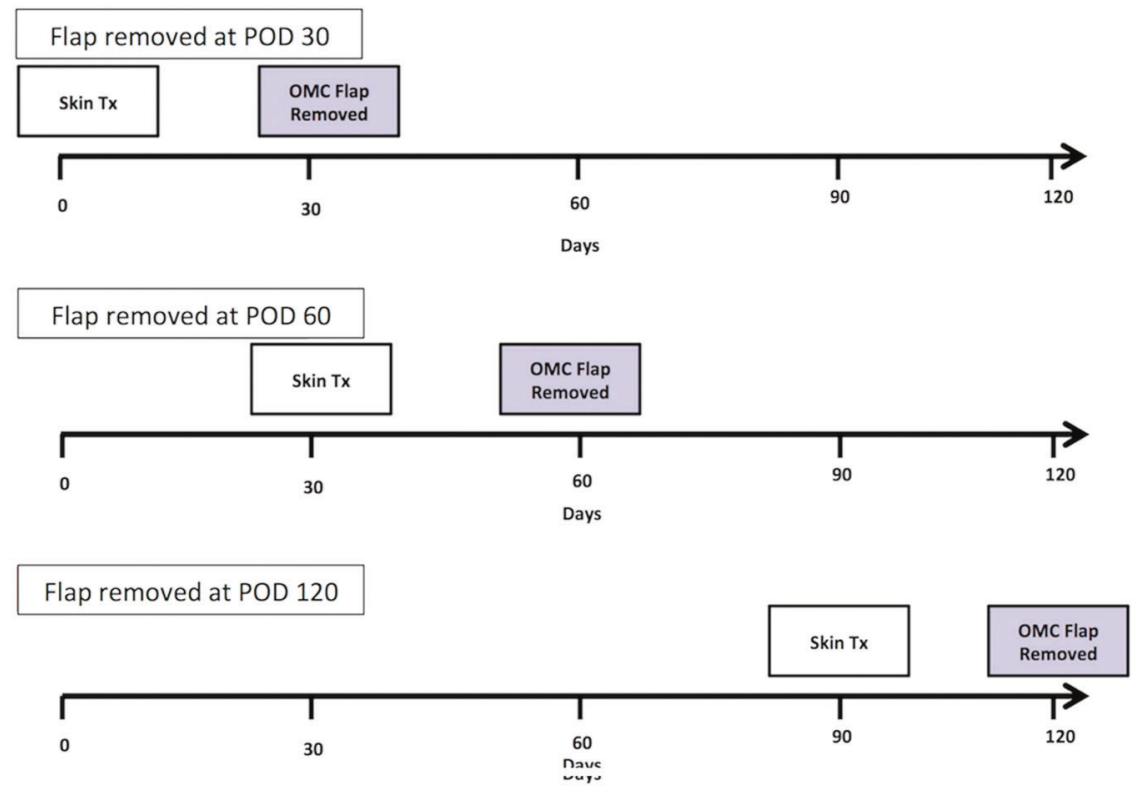

b

Pre-removal of OMC Flap
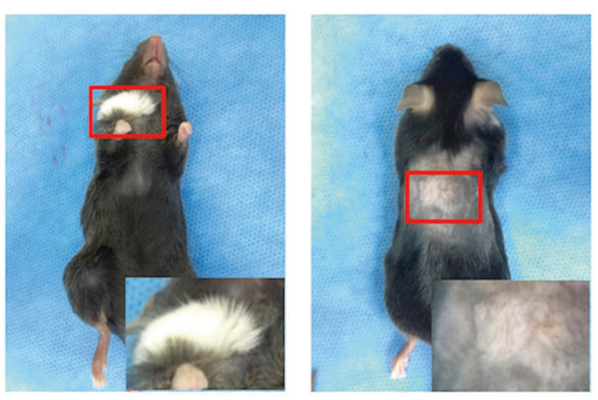

60 Days Post-removal of OMC Flap
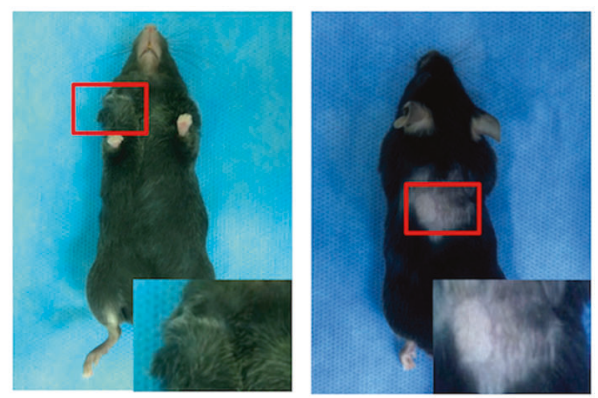

C

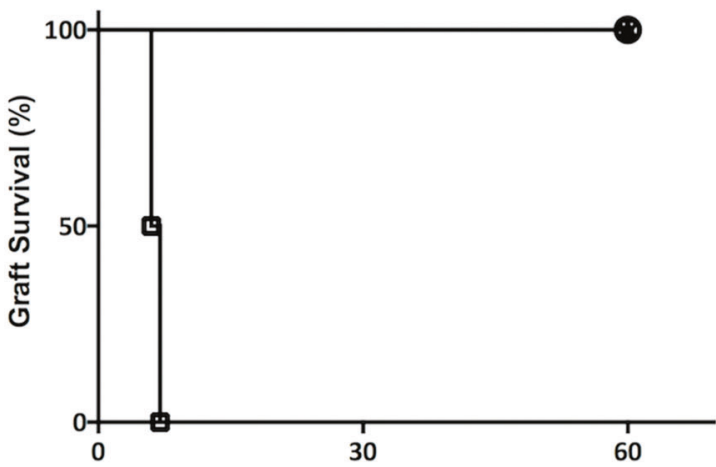

$\begin{array}{lll}\text { Ð Skin Graft w/o VBMT } & n=4 \\ \text { 7 Skin Graft w/ VBMT } & n=4 \\ \text { - Flap Removed at POD } 30 & n=4 \\ \text { - Flap Removed at POD } 60 & n=4 \\ \text { - Flap Removed at POD } 120 & n=4\end{array}$

POD of Skin Graft After Removed OMC Flap

Fig. 6 Survival of the skin graft is maintained after removal of the OMC flap. a Timeline of OMC flap removal following skin transplantation. b Secondary skin grafts were viable at 60 days post-OMC flap removal. c Robust tolerance of the skin allograft ( $>60$ days) was not affected by the timing of the OMC flap removal (POD 30,60, or 120).

were conducted in accordance with the Guide for the Care and Use of Laboratory Animals of the National Institutes of Health and were approved by Chang Gung Institutional Animal Care and Use Committee (no. 2013031803). Balb/c (H2 $\left.{ }^{\mathrm{d}}\right)$ and $\mathrm{C} 57 \mathrm{BL} / 6\left(\mathrm{H} 2^{\mathrm{b}}\right)$ mice were respective donor and recipient strains, representing a full $\mathrm{MHC}$ mismatch. $\mathrm{C} 3 \mathrm{H}\left(\mathrm{H}^{\mathrm{k}}\right)$ mice served as a third-party donor. Syngeneic control transplants were performed using C57BL/6 $\left(\mathrm{H} 2^{\mathrm{b}}\right)$.

\section{VBM transplantation}

The murine transplant model used in this study was previously described by Lin et al. using a sutureless cuff technique. ${ }^{52}$ Briefly, for the donor VCA harvest, the groin of the donor mouse was shaved and disinfected with alcohol. An incision was made parallel and $1 \mathrm{~cm}$ cephalad to the groin crease. Femoral vessels were identified and dissected using an operating microscope (Leica M620, eyepieces: 912.5; Leica, Wetzlar, Germany) to the iliac origin; 
a

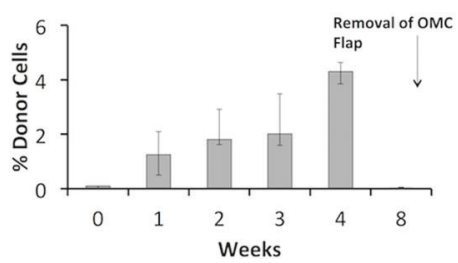

b
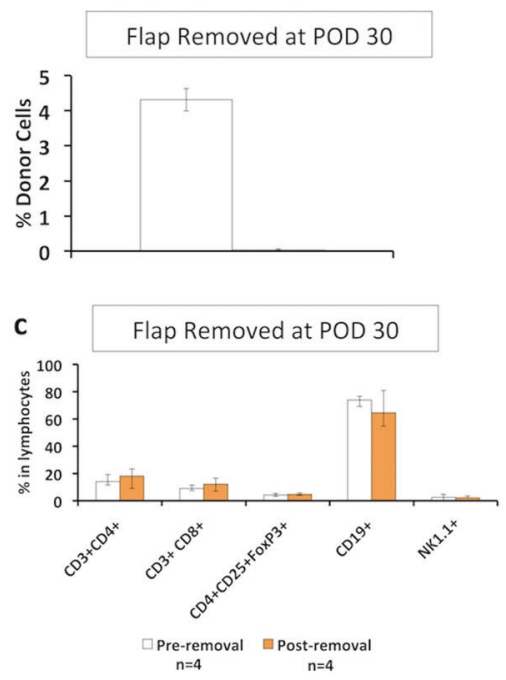

Fig. 7 Removal of the OMC flap at different time points did not affect graft survival. a Peripheral chimerism levels peaked at POD 30. b Peripheral chimerism was not detected after flap removal. c The percentage of peripheral lymphocytes after removal of the OMC flap did not change significantly (Wilcoxon matched-pairs signed-rank test, $p>0.05$ ). Data are expressed as the median and range from four mice per group.

small proximal branches were ligated. Following division, the femoral vessels were fitted with polyimide cuffs (Vention Medical, Denver, CO, USA; iliac artery/femoral vein inner diameter: 0.404 $\mathrm{mm}$, wall thickness: $0.025 \mathrm{~mm}$ ). The vessel was pulled through and everted over the cuff to expose the endothelial surface and secured with 11-0 nylon ligature. Next, all muscle groups were transected with bipolar electrocautery at the level of the hip joint followed by disarticulation. The hindlimb graft was further reduced in size by disarticulation of the knee to ultimately create a whole-femur OMC flap. Alternatively, a myocutaneous flap was harvested in a similar fashion, excluding the femur, as a VBM-free control.

Recipient preparation: A 1-cm right-sided cervical incision was made from the sternum to the acoustic meatus. Removal of the right submandibular gland facilitated identification and isolation of the external jugular vein and common carotid artery. Both vessels were then divided using 11-0 nylon suture and vascular clamps.

Transplantation technique and graft inset: After placing the graft in the cervical region, the cuffed iliac artery and femoral vein were inserted into the recipient common carotid artery and external jugular vein and secured with 11-0 nylon suture. Adequate flap/graft perfusion was confirmed, and the skin was closed using interrupted 6-0 silk sutures.

Experimental design

VBM transplantation was implied by the use of OMC allografts (alloOMCs). Myocutaneous flaps with concomitant donor BM cell transplantation were used as a CBMT model. Syngeneic OMC flap transplantation was used as a control for graft acceptance, and myocutaneous allograft (alloMC) transplantation was deemed to be a nonchimeric control. All allograft recipients received combined $\mathrm{CoB}$ and short-term RPM. Experimental groups were designed as follows: (1) high CBMT group $(n=6)$ that included alloMC recipients receiving $1.5 \times 10^{8} \mathrm{BM}$ cell transplantation; (2) low CBMT group $(n=6)$ that comprised alloMC mice receiving $3 \times$ $10^{7} \mathrm{BM}$ cell transplantation; and (3) VBM transplantation group $(n=6)$ that included alloOMC mice (Fig. 1a). The syngeneic group $(n=4)$ that comprised OMC flap recipients without treatment and the no CBMT group $(n=6)$ that included control alloMC recipients without CBMT were used as controls.

To test the importance of continuous posttransplant VBM presence in the recipient to induce and maintain graft acceptance, 16 skin graft transplantations were performed at different time points on animals that previously received alloOMC. The alloOMCs from 12 of the 16 animals were then removed 30 days after skin graft transplantation (Fig. 6a). Three skin graft transplantations were performed on animals that did not receive alloOMC and immunosuppression as negative controls.

Immunosuppression protocol

C57BL/6 allograft recipients were given an intraperitoneal dose of $1 \mathrm{mg}$ of purified anti-CD154 (BioXCell, West Lebanon, $\mathrm{NH}$, USA) diluted in phosphate-buffered saline (PBS) on the day of transplantation and $0.5 \mathrm{mg}$ of purified CTLA4lg (Bristol Myers Squibb, New York, USA) on POD 2. Next, $3 \mathrm{mg} / \mathrm{kg}$ of intraperitoneal RPM (Wyeth Pharmaceuticals, Philadelphia, PA, USA) was given daily for the first 7 days posttransplant and then every other day for a total treatment period of 4 weeks (Fig. 1b).

\section{BM transplantation}

BM was flushed with PBS (Sigma-Aldrich, St. Louis, MO, USA) from femoral bones of Balb/c mice using a 23-gauge needle under sterile conditions. The marrow was mechanically resuspended in 
PBS by gentle aspiration through a 19-gauge needle, and the suspension was sterile-filtered through a nylon mesh. The cells were centrifuged at $1200 \mathrm{rpm}$ for $5 \mathrm{~min}$, resuspended in PBS, and counted. Each recipient received $3 \times 10^{7} \mathrm{Balb} / \mathrm{c}$ BM cells through the lateral tail vein. This quantity represents the number of cells that are also present within the femoral bone.

\section{Secondary skin graft transplantation}

Full-thickness tail skin $(1 \times 1 \mathrm{~cm})$ from Balb/c (donor) was transplanted onto the lateral thoracic wall of $\mathrm{C} 57 \mathrm{BL} / 6$ recipients and secured with 6-0 nylon suture. Skin graft survival was monitored daily for 60 days. Rejection manifested as complete necrosis of the skin graft.

\section{Clinical assessment}

All grafts/flaps were clinically evaluated daily by visual inspection. Allograft acceptance was implied by normal hair growth with an intact cutaneous paddle. In contrast, graft rejection manifested as skin erythema/necrosis and complete hair loss (Fig. 1c).

\section{Analysis of multilineage chimerism}

The presence of donor hematopoietic cell lineages in the peripheral blood of VCA recipients was serially and quantitatively evaluated with lineage-specific surface markers using a FACSCanto II flow cytometer (BD Biosciences, San Jose, CA, USA). Two-color flow cytometry was used to distinguish donor and host mononuclear leukocytes. The percentage of circulating donor cells was calculated as previously described ${ }^{27}$ using fluorescein-conjugated or biotinylated monoclonal antibodies (mAbs) against $\mathrm{H} 2 \mathrm{~d}$ (clone, 34-2-12) and $\mathrm{H} 2 \mathrm{~b}$ (clone, KH95). Mouse IgG2a, K Isotype Ctrl antibody, which is an isotype control for $\mathrm{H} 2 \mathrm{~d}$ antibody staining, was used to block nonspecific binding. Phycoerythrin-conjugated mAbs against lymphocyte markers such as CD3, CD4, CD8, CD19, CD25, FoxP3, NK1.1, TCR V $\beta 5.1 / 2$, TCR V $\beta 8.1 / 2$, and TCR V $\beta 11$ were also used. All antibodies were purchased from BioLegend (San Diego, CA, USA). Twenty thousand events were collected and analyzed. Propidium iodide (PI) staining was used to distinguish live and dead cells. The population of cells with PI-negative staining was then further analyzed. Unique forward scatter (FSC) and side scatter (SSC) properties distinguished the leukocyte populations: low FSC and SSC characterized lymphocytes, high SSC characterized granulocytes, and high FSC and low SSC characterized monocytes. CD45 and CD11b staining were used to distinguish myeloid cells from lymphoid cells. Cells with $\mathrm{CD} 45^{+} \mathrm{CD} 11 \mathrm{~b}^{+}$were considered myeloid cells, whereas cells with $\mathrm{CD} 45^{+} \mathrm{CD} 11 \mathrm{~b}^{-}$were considered lymphoid cells.

Magnetic cell separation

Splenocytes from naive Balb/c $\left(\mathrm{H} 2^{d}\right)$ or $\mathrm{C} 3 \mathrm{H}\left(\mathrm{H} 2^{\mathrm{k}}\right)$ mice were labeled with magnetic beads coated with CD90.2 mAb (Miltenyi Biotech, San Diego, CA, USA), followed by negative selection on the autoMACS Pro Separator (Miltenyi) to isolate antigenpresenting $\mathrm{CD} 90.2^{-}$cells. The purity of the resultant populations was determined by flow cytometry to be $>95 \%$ in all experiments.

Mixed lymphocyte reaction

Splenocytes from naive $\mathrm{C} 57 \mathrm{BL} / 6\left(\mathrm{H} 2^{\mathrm{b}}\right)$ mice and VCA recipients labeled with Violet Proliferation Dye 450 (VPD, BD Biosciences) were cultured in MLR medium in triplicate as previously described. ${ }^{14}$ Stimulator cells (splenocytes from naive Balb/c mice or third-party $\mathrm{C} 3 \mathrm{H}\left(\mathrm{H} 2^{\mathrm{k}}\right)$ ) were treated with $25 \mu \mathrm{g} / \mathrm{ml}$ mitomycin $\mathrm{C}$ (Sigma-Aldrich) for $10 \mathrm{~min}$ at $37{ }^{\circ} \mathrm{C}$ under $5 \% \mathrm{CO}_{2}$. Stimulator cells $\left(4 \times 10^{5}\right)$ were cocultured with responder cells $\left(2 \times 10^{5}\right)$ in 96-well $\mathrm{U}$-shaped plates for 4 days at $37^{\circ} \mathrm{C}$ under $5 \% \mathrm{CO}_{2}$. Proliferation was assessed based on the dilution of VPD 450 and detected by flow cytometry using a UV laser as the excitation source. T cell proliferation was measured by gating the $C D 3^{+} \mathrm{CD}^{+} \mathrm{VPD}^{+}$or $\mathrm{CD}^{+} \mathrm{CD}^{+} \mathrm{VPD}^{+}$areas.

\section{IHC staining}

IAd staining. IHC testing for thymic, $\mathrm{LN}$, and spleen chimerism was performed as previously described. ${ }^{27}$ Briefly, sections were prepared from tissues frozen in Tissue Tek (Microm Microtech, Francheville, France) and sliced with a cryostat (Thermo Scientific, West Palm Beach, FL, USA). After fixation with acetone (Sigma) and blocking with $10 \%$ fetal bovine serum (Invitrogen, Carlsbad, CA, USA) in PBS, specimens were incubated with biotinylated IAd mAb (BD Bioscience) and developed with streptavidin-conjugated horseradish peroxidase (BD Bioscience) and 3-3 diaminobenzidine (BD Bioscience) for $1 \mathrm{~min}$. Counterstaining was performed using hematoxylin (Leica).

Foxp3 staining. To detect Foxp3 cells in the skin of OMC grafts, sections of $5-\mu \mathrm{m}$ thickness were briefly prepared from paraffinembedded specimens and sliced with a cryostat (Thermo Scientific, West Palm Beach, FL, USA). After deparaffinization, rehydration, and blocking, specimens were incubated with FoxP3 $\mathrm{mAb}$ (eBioscience), followed by secondary and tertiary Ab incubation, which were Rabbit Anti-Rat and Polymer Anti-Rabbit with streptavidin-conjugated horseradish peroxidase (DAKO), respectively. Samples were then developed for color with 3,3'diaminobenzidine (Leica) for $10 \mathrm{~min}$ and counterstained with hematoxylin (Leica).

Statistical analysis

Graft survival was analyzed using Kaplan-Meier method and compared for differences using log-rank test. Wilcoxon matchedpairs signed-rank test and Mann-Whitney $U$ test were used to compare two groups of paired or unpaired data with $n<30$, respectively. Friedman's analysis of variance and Kruskal-Wallis test were used to compare three or more groups of paired and unpaired data with $n<30$. A $p$ value $<0.05$ was considered statistically significant.

\section{ACKNOWLEDGEMENTS}

This work was supported by grants from the Ministry of Science and Technology of Taiwan, China (MOST 106-2314-B-182A-048-MY3) and Chang Gung Medical Foundation (CMRPG3B0261, CMRPG6F0601-3, and CMRPG3C121-3). We are thankful for the technical assistance provided by Nian-Yi Hsu, Hsien-Tang Lin, and Shu-Ping Yeh.

\section{AUTHOR CONTRIBUTIONS}

C.-H.L.-Literature review, study conceptualization, data collection, surgeon, author. M.R.A.-Literature review, data collection, in vitro study, data analysis, author. H.-Y.C., A.Y.L.W., W.-Y.C., C.-H.L., W.P.A.L., and F.-C.W.-Data interpretation. G.B.-Literature review, study conceptualization, data interpretation.

\section{ADDITIONAL INFORMATION}

Competing interests: The authors declare no competing interests.

\section{REFERENCES}

1. Shores, J. T., Brandacher, G. \& Lee, W. P. Hand and upper extremity transplantation: an update of outcomes in the worldwide experience. Plast. Reconst. Surg. 135, 351e-360e (2015).

2. Petruzzo, P. et al. The International Registry on Hand and Composite Tissue Transplantation. Transplantation 90, 1590-1594 (2010).

3. Dean, W. K. \& Talbot, S. G. Vascularized composite allotransplantation at a crossroad: adopting lessons from technology innovation to novel clinical applications. Transplantation 101, 452-456 (2017).

4. Murray, J. E. Organ transplantation (skin, kidney, heart) and the plastic surgeon. Plast. Reconstr. Surg. 47, 425-431 (1971).

5. Wendt, J. R., Ulich, T. R., Ruzics, E. P. \& Hostetler, J. R. Indefinite survival of human skin allografts in patients with long-term immunosuppression. Ann. Plast. Surg. 32, 411-417 (1994).

6. Brandacher, G., Lee, W. P. \& Schneeberger, S. Minimizing immunosuppression in hand transplantation. Expert Rev. Clin. Immunol. 8, 673-683 (2012). 
7. Fryer, M. et al. Exploring cell-based tolerance strategies for hand and face transplantation. Expert Rev. Clin. Immunol. 11, 1189-1204 (2015).

8. Ildstad, S. T. \& Sachs, D. H. Reconstitution with syngeneic plus allogeneic or xenogeneic bone marrow leads to specific acceptance of allografts or xenografts. Nature 307, 168-170 (1984).

9. Sharabi, Y. \& Sachs, D. H. Mixed chimerism and permanent specific transplantation tolerance induced by a nonlethal preparative regimen. J. Exp. Med. 169, 493-502 (1989).

10. Colson, Y. L. et al. Durable mixed allogeneic chimerism and tolerance by a nonlethal radiation-based cytoreductive approach. J. Immunol. 157, 2820-2829 (1996).

11. Mahr, B., Granofszky, N., Muckenhuber, M. \& Wekerle, T. Transplantation tolerance through hematopoietic chimerism: progress and challenges for clinical translation. Front. Immunol. 8, 1762 (2017).

12. Sachs, D. H., Kawai, T. \& Sykes, M. Induction of tolerance through mixed chimerism. Cold Spring Harb. Perspect. Med. 4, a015529 (2014).

13. Ildstad, S. T., Leventhal, J., Wen, Y. \& Yolcu, E. Facilitating cells: translation of hematopoietic chimerism to achieve clinical tolerance. Chimerism 6, 33-39 (2015).

14. Wekerle, T. et al. Allogeneic bone marrow transplantation with co-stimulatory blockade induces macrochimerism and tolerance without cytoreductive host treatment. Nat. Med. 6, 464-469 (2000).

15. Chen, J. et al. Effect of the vascularized bone components on the survival of vascularized composite allografts. J. Surg. Res 224, 132-138 (2018).

16. Cohen, M., Mohanakumar, T., Mackinnon, S. E. \& Tung, T. H. Chimerism after vascularized limb versus bone marrow transplantation. J. Reconstr. Microsurg. 22 375-384 (2006)

17. Suzuki, H. et al. Vascularized bone marrow transplantation: a new surgical approach using isolated femoral bone/bone marrow. J. Surg. Res. 89, 176-183 (2000).

18. Janczewska, S., Ziolkowska, A., Durlik, M., Olszewski, W. L. \& Lukomska, B. Fast lymphoid reconstitution after vascularized bone marrow transplantation in lethally irradiated rats. Transplantation 68, 201-209 (1999).

19. Durlik, M. et al. Tolerance induction following allogeneic vascularized bone marrow transplantation-the possible role of microchimerism. Transpl. Int. 11 (Suppl 1), S299-S302 (1998)

20. Morrison, S. J. \& Scadden, D. T. The bone marrow niche for haematopoietic stem cells. Nature 505, 327-334 (2014).

21. Peled, A. et al. Dependence of human stem cell engraftment and repopulation of NOD/SCID mice on CXCR4. Science 283, 845-848 (1999).

22. Gordon, C. R. et al. Review of vascularized bone marrow transplantation: current status and future clinical applications. Microsurgery 27, 348-353 (2007).

23. Verfaillie, C. M. Hematopoietic stem cells for transplantation. Nat. Immunol. 3 , 314-317 (2002).

24. Hofmeister, C. C., Zhang, J., Knight, K. L., Le, P. \& Stiff, P. J. Ex vivo expansion of umbilical cord blood stem cells for transplantation: growing knowledge from the hematopoietic niche. Bone Marrow Transplant. 39, 11-23 (2007).

25. Grange, C. \& Bussolati, B. Ex vivo manipulation of bone marrow cells to rescue uremia-induced dysfunction for autologous therapy. Stem Cell Res. Ther. 6, 117 (2015).

26. Lin, C. H. et al. Combined anti-CD154/CTLA4lg costimulation blockade-based therapy induces donor-specific tolerance to vascularized osteomyocutaneous allografts. Am. J. Transplant. 16, 2030-2041 (2016).

27. Chen, Y. B., Kawai, T. \& Spitzer, T. R. Combined bone marrow and kidney transplantation for the induction of specific tolerance. Adv. Hematol. 2016, 6471901 (2016).

28. Paix, A. et al. Total body irradiation in allogeneic bone marrow transplantation conditioning regimens: a review. Crit. Rev. Oncol. Hematol. 123, 138-148 (2018).

29. Ding, J. et al. A mouse model of vascularized skin transplantation. Ann. Plast. Surg. 78, 576-581 (2017)

30. Lee, W. P. et al. Relative antigenicity of components of a vascularized limb allograft. Plast. Reconstr. Surg. 87, 401-411 (1991).
31. Domenig, C. et al. Roles of deletion and regulation in creating mixed chimerism and allograft tolerance using a nonlymphoablative irradiation-free protocol. $J$. Immunol. 175, 51-60 (2005).

32. Press, B. H., Sibley, R. K. \& Shons, A. R. Limb allotransplantation in the rat extended survival and return of nerve function with continuous cyclosporin/ prednisone immunosuppression. Ann. Plast. Surg. 16, 313-321 (1986).

33. Ustuner, E. T. et al. Long-term composite tissue allograft survival in a porcine model with cyclosporine/mycophenolate mofetil therapy. Transplantation 66, 1581-1587 (1998).

34. Santiago, S. F. et al. Heterotopic sternum transplant in rats: a new model of a vascularized bone marrow transplantation. Microsurgery 19, 330-334 (1999).

35. Yazici, I., Carnevale, K., Klimczak, A. \& Siemionow, M. A new rat model of maxilla allotransplantation. Ann. Plast. Surg. 58, 338-344 (2007).

36. Nasir, $\mathrm{S}$. et al. New composite tissue allograft model of vascularized bone marrow transplant: the iliac osteomyocutaneous flap. Transpl. Int. 23, 90-100 (2010).

37. Gray Parkin, K. et al. Expression of CD28 by bone marrow stromal cells and its involvement in B lymphopoiesis. J. Immunol. 169, 2292-2302 (2002).

38. Orlic, D. et al. Interleukin-7R alpha mRNA expression increases as stem cells differentiate into $\mathrm{T}$ and $\mathrm{B}$ lymphocyte progenitors. Exp. Hematol. 25, 217-222 (1997).

39. Mansour, A. et al. Osteoclast activity modulates B-cell development in the bone marrow. Cell Res. 21, 1102-1115 (2011).

40. Neumann, B., Klippert, A., Raue, K., Sopper, S. \& Stahl-Hennig, C. Characterization of $\mathrm{B}$ and plasma cells in blood, bone marrow, and secondary lymphoid organs of rhesus macaques by multicolor flow cytometry. J. Leukoc. Biol. 97, 19-30 (2015).

41. Siemionow, M. Z., Izycki, D. M. \& Zielinski, M. Donor-specific tolerance in fully major histocompatibility major histocompatibility complex-mismatched limb allograft transplants under an anti-alphabeta T-cell receptor monoclonal antibody and cyclosporine A protocol. Transplantation 76, 1662-1668 (2003).

42. Muramatsu, K., Valenzuela, R. G. \& Bishop, A. T. Detection of chimerism following vascularized bone allotransplantation by polymerase chain reaction using a $\mathrm{Y}$ chromosome specific primer. J. Orthop. Res. 21, 1056-1062 (2003).

43. Klimczak, A., Agaoglu, G., Carnevale, K. A. \& Siemionow, M. Applications of bilateral vascularized femoral bone marrow transplantation for chimerism induction across the major histocompatibility (MHC) barrier: Part II. Ann. Plast. Surg. 57, 422-430 (2006).

44. Muramatsu, K., Kurokawa, Y., Ihara, K., You-Xin, S. \& Kawai, S. Donor cell engraftment in recipient lymphoid tissues after rat limb allograft. J. Surg. Res. 124 38-44 (2005)

45. Gameiro, J., Nagib, P. \& Verinaud, L. The thymus microenvironment in regulating thymocyte differentiation. Cell Adh. Migr. 4, 382-390 (2010).

46. Kurtz, J., Ito, H., Wekerle, T., Shaffer, J. \& Sykes, M. Mechanisms involved in the establishment of tolerance through costimulatory blockade and BMT: lack of requirement for $\mathrm{CD} 40 \mathrm{~L}$-mediated signaling for tolerance or deletion of donorreactive CD4+ cells. Am. J. Transplant. 1, 339-349 (2001).

47. Barth, R. N. et al. Vascularized bone marrow-based immunosuppression inhibits rejection of vascularized composite allografts in nonhuman primates. Am. J. Transplant. 11, 1407-1416 (2011).

48. Brazio, P. S. et al. Infused bone marrow fails to prevent vascularized composite allograft rejection in nonhuman primates. Am. J. Transplant. 15, 2011-2012 (2015).

49. Neuhaus, P., Klupp, J. \& Langrehr, J. M. mTOR inhibitors: an overview. Liver Transplant. 7, 473-484 (2001).

50. Coenen, J. J., Koenen, H. J., van Rijssen, E., Hilbrands, L. B. \& Joosten, I. Rapamycin, and not cyclosporin A, preserves the highly suppressive CD27+ subset of human CD4+CD25+ regulatory T cells. Blood 107, 1018-1023 (2006).

51. Strauss, L. et al. Selective survival of naturally occurring human CD4+CD25+ Foxp3+ regulatory T cells cultured with rapamycin. J. Immunol. 178, 320-329 (2007).

52. Lin, C. H. et al. The neck as a preferred recipient site for vascularized composite allotransplantation in the mouse. Plast. Reconstr. Surg. 133, 133e-141e (2014). 